\title{
Therapeutic intervention and high-order adjustments of recursion
}

\author{
Cláudio Alexandre S. Carvalho \\ LIF - Language, Interpretation and Philosophy, Coimbra, Portugal
}

\begin{abstract}
The introduction of second-order cybernetics on therapeutic practices required a deeper acknowledgement of the role and purpose(s) of the therapists on the transitory system they create with their patients. This requirement, forced their self-reflection as both observers and agents of change or irritation of communicative and cognitive processes. Another major consequence concerned the understanding of dysfunctions, no longer conceived as "real" independently from an epistemic standpoint that begins by delineating its composing elements and relations using a particular notation. The insertion of "second-order sciences" in therapeutic models involving psychic and communicative systems lead to a more sensible attunement of recursive interventions, due to a greater attention to high-order processes of punctuation of events and learning acquisitions. Focusing on the case of family therapy, we sustain that the acknowledgement of uncertain repercussions of interventions in the equilibrium of a system (or organization) is not a sign of weakness of therapy. Supported on Luhmann's account of the family system, and stressing some of the affinities of his operative constructivism with second order cybernetics, we understand the uncertainties of therapy as 1) a consequence of the "individuation" of modern society and 2) a call for renewed and creative forms of therapeutic intervention. Through a brief presentation of Circular Questioning and of the resource to Reflecting Teams, we inspect how the therapeutic observation is dependent upon sequences of reentry that assume different levels of description. Acknowledging the consequences of modern forms of differentiation, Systemic therapy, but also forms of psychotherapy, underlined the frailties of pre-established modes of assessment and intervention. More profoundly, they denounced the insufficiency of normative models imposed to persons, "fixing" the coupling between the psychic and communicative forms. In a wide range of disorders, approaches that dispense with the 1) active enrolment of the patient in the changing process and 2) the recursive evaluation (and readjustment) of the punctuation of sequences, its self-reflection, tend to originate high order problems. This reopens the discussion of the unacknowledged assumptions of therapies within a new theoretical framework, concerning their first-order observers (both client/patient and therapist(s)), and the various levels whose distinctions guide their interaction.
\end{abstract}

url:

\section{Introduction}

Therapeutic practices are always the product of a particular kind of social differentiation and in them are identified, treated and regulated, societies' and individual problems, dysfunctions and anxieties. Due to its "object", process and "goals", therapeutic intervention reflects and treats complexity of society. The typification (and subsequent attribution) of "disorders", for instance in statistical manuals, that seem permanently under siege due to their share of disputed principles and criteria, is the more conspicuous instance of this process. This kind of mapping and anticipation of the outcomes of a certain phenomenon of suffering or dysfunction affects the lives of millions of people worldwide. Even if some kinds of psychotherapy are able, in part due to the particular problems they address, to "suspend" or even reject those categorizations, allowing a more dynamic and interactive understanding, the question of how to identify and treat a problem is not dissolve. On the contrary,

Corresponding author: Cláudio Alexandre S. Carvalho; e-mail: kraftcasc@gmail.com 
the absence of strict guidelines makes more pressing the questions concerning the responsibility of the therapist and the epistemological model that frames his practice.

If there is something the therapist knows -and that is confirmed right at the first contact with a new mental or communicative problem-, is that those modes of organizing symptoms and predicting outcomes cannot contain the uncertainty that, by his intervention, he tacitly accepts to extend in order to understand and manage it. This approach seems obvious, but it already assumes that psychic and social systems differ from trivial machines that can (and must) be fixed back to a given state, in order to provide an invariable performance.

Even if their observation always follow some guiding distinctions, certain kinds of dysfunctions seem to dispense with a detained thematization of the second-order level of therapeutic intervention, frequently due to their linear settings where the path from the symptom to the treatment is straightforward and unproblematic. This could be the case in physiotherapy or even in an ideal(ized) pharmacological intervention, where one must restore a trivial function with a presumed neutrality and clear goals. Even so, that level of observation and learning would prove beneficial in executing treatment plans, preventing relapses and, at a higher level, leading to an evaluation of the outcomes of a system that "manages" dysfunctions ${ }^{\mathrm{i}}$.

Due to its complexity, most of mental illnesses and communicative problems demand the observation and intervention on distinctions governing first-order selective behavior, not only concerning the response of the client to some treatment plan, but also upon the distinctions that guide the therapist behavior on the transient system inaugurated with his/her "appearance". This new system must be able to describe a circulus vitiosus, and additionally, through a correction or reframing of its circularity, to turn it into a circulus virtuosus. Easier said than done!

Recursion, as formalized in mathematics, means that not only the result but also the distinction(s) that produced it, constitute the grounding of the next operation of a system. The circularity here implied, as in a self-pointing arrow, can only acquire meaning in its "infinite in finite guise", with the presence of an observer that identifies the sequences of a form that re-enters in itself. It "can never occur on the page of symbols" (Kauffmann 1987, p. 58). In fact, through the simple inversion of a vector, recursion of a simple form can result in highly complex patterns such as the one present in an inner door of La Seo Cathedral in Zaragoza. Like in various activities and organizations that depend on minimal sequences of re-entries, such as the adjustments required to drive a vehicle, only with a breakdown will the distinction that frames a given indicational space will be thematized and eventually revised.

In therapy, one can also describe processes of readjustment of recursion, but at a level of complexity and contingency difficult to formalize. If, instead of explaining a "simple" process of readjusting one's behavior according with the variables of a pathway, we consider the requirements needed to actually drive a motor vehicle (to fulfill certain visual and motor requirements, be able to interpret signs, acquiring a driving license, make an insurance...) we have a glimpse of the complexity of therapy and the way it differs from both formal and trivial processes. On the other hand, as it happens when considering activities such as driving, one can circumscribe therapy to the realm of clinical interaction or he may eventually try to confirm the efficacy of a therapeutic theory at the logical level. In both cases, the observation of circularity depends upon a selection that, in some sense, is arbitrary.

Since its first delineations, the project of cybernetics has been caught in a certain gap between a formal understanding of organization based the selection of bits of information and the access to the "actual" organization of living beings and social systems, whose functioning involves a dynamic and 
yet stable self-organization. Psychic and communicative forms of organization involve much more than a right way of functioning, otherwise the problems they create in their operations could be solved inducing the imitation of a pattern, through manipulation or even coercion.

Second order therapy departs from the recognition that the circular recursion that maintains the reproduction of a system cannot be directly observed nor altered and, at the limit, a given change is discontinuous with a therapeutic intention, that is it cannot be fully considered an "effect". This forces the "observing system" to reflect on the distinctions that guide its intervention in order to make possible a therapeutic outcome. Paradoxically, this is only possible considering the effects of a theory, the way its product re-enter in its own processes. This turn obeys von Foerster's Aesthetic Imperative: "if you desire to see, learn how to act" (1984 b, p. 61) ${ }^{\text {ii. }}$

In contemporary society, Systemic therapy emerged, in open counter-movement to some forms of psychotherapy, as a response to a growing awareness that illnesses and dysfunctions could not be described -and consequently assessed and treated-isolating its symptomatic manifestation in one individual or in punctual problems. In the present paper, we aim to show, by a conceptual inquiry illustrated with some examples, how only with the gradual introduction of cybernetics of second order in several models of Systemic therapy, has it been possible to acknowledge, in their full extension, high-order processes of cognition and communication and their non-linear patterns. We must also be aware that this new background based on the description and optimization of system's self-reference, enabled or, at least, facilitated, the proliferation of forms of intervention no longer guided by the strict therapeutic code. It originated an "inflation of expectations", directed towards the improvement of performances also in the contiguous fields of practice of counseling and coaching (Luhmann 1983).

The increasing use of concepts and models of second order cybernetics (and systems theory), lead to a generalization of self-reflection and questioning of the purpose of the therapist. Finally, it conducted to the somewhat awkward recognition that the idea of the therapist as the agent or commander of change -and the related ideas of control and equilibrium- needed to be reconsidered, if not altogether abolished as dangerous presumptions. Concepts such as neutrality and responsibility suffered, particularly from the beginning of the 8o's onwards, so much metamorphoses that one is forced to wonder if anything remains from their first meanings in cybernetics. Various currents of therapy became aware that, not only in undifferentiated forms of help, but also in systemic therapeutic interventions "we do not see that we do not see. This I will call a second order deficiency, and the only way to overcome such deficiencies is with therapies of second order" (Foerster 2002, p. 284).

From an historical point of view, the importance of high-order patterns of recursion and the way they involve epistemological and ethical standpoints, resulted paradoxically from the richness of individual sessions, which showed the importance of the social context (of attributions and expectations) both on the appearance (etiology), evolution and (sometimes) reinforcing of mental suffering and illness. This led to a (late) denouncing of the artificiality of the strict individualization of disorders and a large reorganization of therapeutic services in Psychiatry, gathering contributions of Social Service. In various currents of Psychoanalysis, there has also been a growing awareness of the insertion of the individual in a given social context, especially to the normative perspectives it endorses in the path towards "cure".

With its receptivity to the evolution of system's theory and second order cybernetics, it was in Family therapy that the idea of disorders as objectively present in a given subject disconnected from the participation of the psychic system in the social relations, was definitely put into question. However as noted by G. Schiepek "Family therapy, in its different variants, brings with it an 
enormous extension of the therapeutic space to act (...) but it also leads to a greater need for

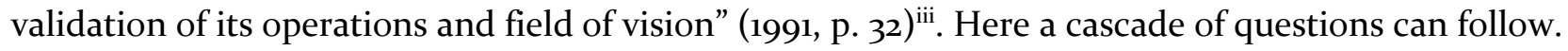
Can this attention to processes of observation and self-questioning lead to a "overloading" of the therapeutic system? Has it simply a theoretical value or can it lead to an improvement of assessment? Are there models that can generalize the management of the complex and contingent processes involved in dysfunctional intimate relations?

These questions could be addressed by Ashby's Law of Requisite Variety, which adapted to therapy means that the variety of the observed system can only be managed, controlled or regulated, if the observing system is capable to match that variety in order to adjust it (by increasing or decreasing it). However, some models of therapy came to realize that, by becoming a model of the observed system they needed to account for the way their descriptions, predictions and interventions, depended on their own observations of the self-organizing systems. This inclusion of the observer on the observed is full of consequences for the way one can conceive the sequences of recursion in therapy.

\section{Context and brief history of the origins of "second order therapy"}

Even if prior to the introduction of cybernetics in social and behavioral sciences, classical models of Systemic Therapy hold much in common with the theoretical approaches of first-order cybernetics. Such affinity seems inherent to the concept of therapy itself. It is anchored on the assumptions of contiguity between action and reaction, of control of therapeutic process and its re-assessments, and also, on the idea that equilibrium must be the ultimate goal of a given individual or organism. The recursivity of first-order cybernetics consisted on the transition from the description of states or products of an observed system to the "inscription" of an intended state, through negative feedback.

By developing a thread that Freudian psychoanalysis left virtually unexplored, namely the importance of communicative dynamics on psychic dysfunctions of the "symptom bearer", authors like V. Satir began discovering how some individual imbalances could only be partially explain through introjected objects and psychodynamics, and were dependent on a present relation with a "significant other".

Structural Family therapy of S. Minuchin was particularly keen in determining the precise external and internal boundaries of a given system and, through prescription of rituals, restore its sense of purpose and identity. His observation of the system was close to that of a choreographer that provides a script that has little room for the dancer's state of spirit (e.g. Minuchin and Fishman 1981, pp. 249-253). If any adjustment was needed it was made in order to correspond to the intended performances and goals of each subsystem of the family in order to attain equilibrium. Minuchin's work proved extremely efficient even relying on such linear and directive approach, mostly due to his inventive prescriptions of rituals. Another reason for its success is the way it reinforces pre-given models of organization, assuming a right way to distribute power and resources within the family. Family equilibrium was considered dependent upon the maintaining of strict rules of three main subsystems: the couple/marital system, the children, and the genders. However, the evolution of the intimate system, and the generalization of new normative expectations, leaded to the challenging of fixed gender roles and pre-establish models of organization.

The diffusion of family structures opposing a unified model (supported on the effective myths of the "traditional" family) and its concomitance with the progress of therapeutic practices, makes it hard to determine what was consequence of the generalization of new societal demands and expectations (new semantics of intimacy and gender), and what was in fact a "discovery" of therapy, namely concerning its new emphasis on the self-organization of the family. 
The explicit influence of Cybernetics on Systemic Therapy, leaded to a new awareness of the internal dynamics of the family, and allowed the recognition of patterns and modes of intervention not restricted to the trivial scheme input-output. At the same time that these models recognized the patterns of selection of the observed system, they were forced to acknowledge the contingency of those processes and their improbability.

The initial project of Mental Research Institute [MRI] in Palo Alto, remains important in order to differentiate Systemic Therapy. Brief Therapy and Strategic therapy of J. Haley, proposed pragmatic models that focused on the need to determine the problematic situation as precisely and "objectively" as possible. They refused predetermined set of psychopathological dysfunctions and criticized the obsession of locating the causes of the problem in a ominous and determining past. Along with the basic refusal in considering any pathology in isolation from the communicative relation, and a clear "isolation" of problems, systemic therapy should set, from the very beginning, viable of goals and a limited period to work on the necessary change. What on a immediate observation tends to be described as a pathology can be a sign of the mental and communicative well-being. In his dialogue with Bernhard Pörksen, Foerster says that, at the beginning of therapy "certain is only that this man endures a misfortune" (1999, p. 55). Therapy must proceed only if there is "any theme of a communication that values something as undesired and changeable" (Ludewig 1992, p. 116). These requirements were absent from the leading models of psychiatry and psychoanalysis, that for long, remained engaged with an integral change of the individual.

These advances were deeply influenced by M. Erickson practice. He paved the way to new forms of inducing change in a clinical problem through non-conventional and counter-intuitive methods. The frequent reference to his resort on hypnosis, that remains unconsidered as a "dialogue" with the unconscious, obstructs an understanding of the way he approached a problem focusing on the strengths of a client: "all a therapist does is provide a context in which a client can utilize his own resources to achieve the necessary change(s)" (Keeney 1983). This required a capacity of recognizing and using clients own language in order to apply a wide variety of technics that conduct or facilitate a new perspective on a problem. Erickson's great technical advancement in diagnosing and treating problems can be described as the adaptation of Aikido do psychotherapy, i.e. adopting a sensible approach to the tendencies and capabilities of the patient, not opposing but redirecting them ${ }^{\mathrm{iv}}$.

But despite Erickson's breakthroughs, particularly in his use of paradoxes and confusion as a way to induce a seeking for order in mental or communicative dysfunctions, it was Bateson that, for the first time, placed Cybernetics at the core of an epistemic refoundation of human and social sciences. The classical works of leaded by Watzlawick et. al. $(1967,1974)$, were greatly responsible for the diffusion of therapeutic approaches inspired by Bateson theoretical and clinical work. However, these works stripped Bateson's teachings to some core themes, especially concerning the levels of description/notation (and change) of clinical problems, but also the ability to observe (and intervene in) distinctive patterns of feedback loops.

This shifts the attention to the "observing system" that "constructs" the relevant regularities and patterns, and reflects on its own entitlement for stimulating change in a given ecosystem. A firm defense of Bateson's refusal of the concept of power, lead some authors to suppose the reduction of the role of the therapist to a minimum (Golann 1988, pp. 55-6). But, if second-order observation helps prevent directive approaches, it does not necessarily impose an ethical commitment to nonintervention nor a anticipation of outcomes. 
In Change, Watzlawick, Weakland and Fisch recognized the earlier concept of "family homeostasis“ proposed by Don Jackson, as being present in various forms of dysfunctional communication. In the various cases exposed by those authors, the system holds to some behaviors that even if well intended and "rational", resulting from the compression (or economization) of the range of possible and meaningful interaction along a relationship (Jackson 1965, pp. 9-12), lead the problems to aggravate. These cases required what they designate a first order change, consisting, according to their application of theory of types, in a new combination of elements. That interruption required a linear and punctual change of behavior. But sometimes, within a the set of available changes none could lead to a resolution of the problem, and it was required a second order change, consisting in a "reframing" of an entire set of objects and relations, change of change. This was achieved interrupting the "more of the same" cycle, which imposes itself mainly due to the holding on past successful behavior that become inoperative (in face of a structural or organizational change). According to the authors, the cognitive access to this meta-level or meta-reality, marks an irreversible step for the system (Watzlawick, Weakland and Fisch 1974, p. 99). In this level, one gets a new perspective on others and one's own behavior, being able to resignified or accept their meaning. Watzlawick simplified also the distinctions to two levels of reality, a first order, consisting in the data gathered by the senses and second order, resulting from the attribution of meaning and value to those perceptions (Watzlawick 1991). Although based on self-reflective practices, this approach did not withdraw from the idea that therapy "applied" to an observed system.

These authors' questioning of the psychoanalytical model of intervention was not exclusively theoretical, criticizing the tendency to view the present as a function of the past. It applied also to the idea that, through "training analysis" it was possible to assure that an individual analyst would be aware of (and able to control) the dangerous effects of countertransference. At least in part, it was the absence of a parallel model of formation of systemic therapists that lead to the need to resource to "external" solutions that could regulate derailing processes of intervention, namely those where intervention lead to an aggravation of the problem(s). The Milan group will respond to this necessity with the creation of a "observing team" that observes and analyses therapeutic sessions through a one-way mirror.

Deeply influenced by the MRI group, the Milan associates will pursue even further the idea that individual symptoms or communicative "knots"v, can be read as efforts to maintain or achieve homeostasis. This assumes two frequent forms, an attempted resolution that results in a dysfunction or a problem created in order to prevent a greater problem. These authors privilege the construction/narration of stories as the way to access the rules that structure a given family. In communicative patterns, one would not find necessary scripts and patterns of interaction, but selections that iterate various assumptions occluding alternatives. A problem arises when those stories lose their aggregating power, are somehow broken or made impossible by the evolution/maturation of the system. Circular questioning is the provided mode to access the inner states of the members of the family and to get a new perspective on the system's "blocked" circularity.

The Milan model is characterized by a final intervention under the form of prescriptions resulting from the observation of the linguistic behavior of the family members. The space interval between session should be long enough to perform the prescriptions and evaluate the results. At the same time, this model, that will be continued further improved by Selvini-Palazzoli, assures that the therapist not only maintains his (directive) position, but see it reinforced by the neutrality certified by the therapeutic observing team. 
In this model the therapist must maintain both her autonomy and distance, not "taking sides" for any members. The concept of neutrality was applied to all elements of therapy, beginning with therapeutic team. It was a way to prevent a judicative bent observable in the therapeutic approaches that, accordingly with the model of first-order cybernetics, presume to access the objective truth of the observed system. Since their approach privileges the construction of a common story that grants the recognition of the motives and expectations of oneself and other, it should endorse all points of view. However, 'for many therapists neutrality has been regarded as the cultivation of a position of non-involvement, of not having strong opinions, and of not taking responsibility when necessary the cultivation of the cold and aloof position of a relativist' (Cecchin 1987, p. 405). The observing team could be tempted to comprehend and, at least inherently, subscribe, some types of inadmissible behavior for the sake of the system's maintenance.

One can think of innumerous cases where the equilibrium dynamics of a system is maintained at the costs of a questionable asymmetry, where one person (or a subsystem) is subordinated to another. In such cases, if the therapist abstains from taking a stance he is probably just giving an institutional stamping on an abusive situation or context (e.g. Mackinnon and Miller 1987).

The emotional and physiological responses to some kinds of communicative patterns by the therapist are a kind of ultimate evidence that the neutral position depends upon a fictive and dangerous suppression of human factors from the process of therapy. Instead, in their work, Cecchin and Boscolo tried to show that the outrage or the boredom of a therapist, must not be ignored or rationalized. They derive from a acknowledgement of the importance of one's preconcepts and the way they affect the therapeutic process. When ignored or repressed they lead to dangerous modes of recursion (we will return to this when sketching high-order problems of recursion, see section 5).

Sensitive to the notion of autopoiesis as developed by Maturana, they no longer conceive an objective observed system in which one "drops bombs". Maintaining the importance of collaborative construction of stories, they will become critics of a necessity to "instruct" the system: "it is quite easy for a therapist to experience himself as being a caring person without realizing that the caring can become pity, which in turn subtly implies a disrespectful attitude towards the client" (Cecchin et al. 1992, p. 58).

This new attention to cooperation and dialogue as conditions to access the inner states of problems and conflicts will orient T. Andersen in his implementation of a Reflective Team. In this model's variants, the therapeutic interaction is not observed in a unidirectional way. At certain points, the clients can observe the observing team discussing their problems and hypothesizing their positive aspects and possibilities of improvement. Instead of looking for a ultimate cause, hypothesizing serves the purpose of expanding multiple working plans.

\section{A look into Luhmann's understanding of the intimate system and its pathologies}

These advances in the therapeutic practice concur with some of Luhmann's views on therapy and counselling. Luhmann was keenly aware of the emergence of new forms of therapy that were beyond a strict opposition between observing and observed system. His reflections assume the need to sketch the conditions of a "problem-system" attending to the patterns of recursion of a given problem or conflict, but also accounting for its own re-entries along its (intended) dissolution.

Luhmann's Systems theory is influenced by cybernetic conceptions, particularly in his development of the system's differentiation and creation of its own environment. The different autopoietic cycles of the organic, the psychic and the communicative-, depend upon its selections of information, departing from particular codes based on differences. "Differences are like shifts that can be turned 
"on" and "off" (but never "onoff"). They regulate the flux of energy, without creating the energy itself" (Luhmann 1990, p. 8). And for Luhmann, the creation and managing of information through rules is not static, it unfolds in the sequences of different autopoietic cycles of recursion ${ }^{\text {vi }}$. Paradoxically, the complexity of a given system is dependent upon its operative closure, that is, its capacity to create, through its "internal" elements and patterns of selection, an internal complexity that enables it to identify and "treat" environment complexity. In psychic and social systems, whose selections are based on meaning, this means that operative closure enables cognitive (or informational) openness to further selections.

A lineal model of understanding is unable to account for the complexity involved in these selections and is disarmed to deal with behavior and communication patterns that seem counter-intuitive or simply aberrant.

Luhmann's "operative constructivism" escapes not only ingenuous realism, but also unaffected solipsism that takes the generation of order as a purely arbitrary decision. By attending to the imposition of selective behavior in different systems of modern society, Luhmann have surpassed the classical opposition between object(ivism) and subject(ivism) (e.g. Balsemão Pires 2013). System's theory presents an alternative account of interaction not restricted to the poles of action and experience but also able to attend to the autonomy of communicative process. This autonomy of communication is the key for his conceptions on therapy, given that its sequences guarantee the access to first order interaction and second order observation.

According to Luhmann, in modern society family's autopoiesis results, paradoxically, from its loss of autarky or self-sufficiency that characterized the ancient multifunctional model of families in segmentary and stratified societies. All the functions once contained within societas domestica, were appropriated by functional differentiated systems, and family "only" responds to the whole personality of its members.

The family system poses serious difficulties to the problem-system of therapy, beginning with its delimitation, the way it defines its own borders and contains its internal contingency. Luhmann attended to this problem showing how the internal differentiation of the intimate sphere depends not on given relationships based on blood, affinity or sharing of resources, but upon the generalization of a communicative media that organizes the possible recursions of those elements. What remains throughout the sequences, given the change of the elements and structure, is the identification of the system, through self-reference.

In his early manuscript Liebe - eine Übung, Luhmann stressed that the symbolic medium of communication "Love", particularly his genesis as amour-passion, is more oriented by subjective experience, than by pre-available paths of action (Luhmann 2008: $12 \mathrm{ff}$.) ${ }^{\text {vii. }}$. Like the mediums of Art and Religion, there is no "external" or "objective" reference that guides the system in its autopoiesis. Its psychic and communicative sequences are dependent on events that confirm (or infirm) a coordination of the intimates. So, "[m] uch more than other social systems, the family is an historical system that draws in itself what happens in the relation between consciousness and communication." (Luhmann 199ob, p. 222).

The person is at the center of its reproductions, but by "person" we do not understand an essential interiority nor the psychophysical individual, but an aggregate of communicative and psychic expectations $^{\text {viii }}$. This aggregate constitutes precisely the structural coupling at the center of the family processes. It preserves the operative autonomy of each of those forms but enables coreferences to meaning and coordination schemes grounded on its shared medium: language. Since 
they have different operative mediums, they have distinct operative sequences, that become actualized in the interaction.

Therefore, since the system of intimacy concerns the entire personality of the individual, and its consequences do not involve "roles, but love, a second order observation is advisable. Everyone must orient his [or her] own behavior accordingly to what and how other family members will see. Conflicts are naturally not excluded, but on the contrary: subtle and injuring strategies make possible, that anyone knows that the other knows what he did" (Luhmann 200o, p. 313).

In Luhmann's perspective (and the same holds for systemic therapy that he subscribes ${ }^{\mathrm{i} x}$ ), the patterns of recursion of communicative processes are assumed as the condition to describe the system and, when relevant, observe psychic manifestations through interaction ${ }^{\mathrm{x}}$. The first difference guiding the family system and its reentries, is its basic code, the distinction: personal/impersonal. "Any internal and external experience and action [Erleben und Handeln] is relevant, so long it is personally relevant. In the strong sense of Spencer Brown, the family is a form that reenters the form" (Luhmann 199ob, p. 222) ${ }^{x i}$. But, according to Luhmann's view, "if and how this difference [Differenz], also as distinction [Unterscheidung], can be observed, depend upon the cognitive capacities of an observer" (1990a, p. 198). So, "the mechanism of re-entry is constructed and reproduced by personality, and not by the autopoiesis that is determined by the Eigenstructures of the psychic system" (1990a, p. 202).

"Everywhere the requirements of self-observation of the systems within the systems, and more and more are system's rational solution only attainable at the level of the observation of observations, that is, a sort of precarious dynamic stability" (Luhmann 1990a, p. 210). This is a level of observation of the virtuality of the system. Other modes of social differentiation, relying on an ideal first-order observation that informs all semantic representations of the world, made it inaccessible or banned. In the new conditions of the intimate system of modern society, the idea of a direct access to a ultimate order extracted from the way things are is epistemically and ethically unsustainable. Both due to its "memory" and infinite openness to all events of their members, the system is never fully observable for that would presuppose an access to future selections of its "unmarked" virtuality, but also overcoming of other's and self's non-transparency.

The recursivity of the pair action-cognition, accordingly to Luhmann's model of double contingency, can only be "constructed" departing from interaction. However, the premises or distinctions guiding interaction may not be easily accessed in first order observations. Nevertheless, interaction can take place in particular circumstances, as it occurs in group therapy, where the generative power of language prompts a model of anticipation of expectations and future behavior promoting an implicit or explicit thematization of coordination patterns.

The therapeutic settings already referred, departed from this double difficulty: knowledge can be insufficient to assure adequate recursions of the system; and certain solutions interviewed may not address the problem correctly or, worse, can mask or aggravate it. If one is to be consequent with the epistemic propositions of Luhmann, the therapeutic system has the task of working on the family's inner non-transparency not directly but inserting it in another system. This conforms to a way of "reducing a [form of] complexity through other" (Luhmann 1984, p. 50).

In Luhmann's view, the therapist cannot simply erupt within an already formed system. He creates a new special system of observation (Luhmann 1988). So "the counselling team, the interaction between counselor and client, and finally, the system of the client [Klientensystem], are different systems with their own recursions, own dynamic, own borders and also proper demands on discretion" (Luhmann 2000, p. 393). An entire frankness is doubtful, and the problem-system 
depends on the preservation of the richness of subjectivity. Adapting the saying of the "poet of the intelligence", it must work on "this extraordinary mixture between the fear of not being understood and the terror of being understood"xii.

According to Luhmann's idea of structural coupling between psychic and communicative forms, whose operations are based on meaning, much of the therapeutic intervention consists in working the perception of each order's communicative behavior ${ }^{\text {xiii. }}$. The classic distinction between information, message and interpretation/understanding, elements of communicative unfolding, is a candidate to describe this dynamic. However, the access to the patterns guiding the series of expectations of expectations, is most of the times not evident nor the adequate solutions that can be anticipated. Systemic therapy based on second order cybernetics (but also on Luhmann's Systems Theory), privileges the self-closure of the observed/created system, and its ability to attain an eigenbehavior.

In accordance with the construction of the problem-system, the differentiation of a family or organization from its own environment, through self-reference, brings with it an impossibility to acknowledge its ruling differences from the outside, even if, particularly with the detection of a problem or difficulties, some of the aspects of the system become more conspicuous to an external observer. The therapist must be able to get a familiarity with the interactions and the manifestation of each psychic system but, especially with its guiding distinctions. At the same time, when observing its communications and the manifestation or unfolding of its problems, one must recognize that what can witnessed is always a forced spontaneity of the system similar to some double bind situations where contradictory and impossible demands are posed on the individual, forcing an autonomy: "be spontaneous!". Therefore, according to the epistemic premises, therapy constitutes in itself not simply a model of observation and intervention, but a transitory system whose purpose is to observe and eventually intervene in the organization of another system, departing from its not knowing.

The problem-system, entailing therapist(s) and clients, provides a setting to define and address detected conflicts and/or disfunctions, having language as the common medium between psychic and communicative systems. It grants the ability to reflect on the conditions to express thoughts and feelings, and make clear the coordination of expectations. Nevertheless, if language (verbal and nonverbal) is its the most conspicuous tool, observation cannot be limited to it. Its reflexivity and recursions, must preserve cognitive openness and consider conditions of effective change. The integral commitment of the subject through performative utterances, proposed by speech acts, provides a possible model, a "window through which we can step outside of language" (Foerster 1984: 23). However, it departs from a problematic coincidence, through sequences, between the subject of speech and his social position. A coincidence that is frequently equivalent to an entrapment on one's ego.

All these considerations came to alter some of the presumptions on the role of scientific influence on practices of systemic assistance. The impact of theories is "more in the sense of disciplining imagination, and more strongly of experiences acquired ad hoc with the system of the client, than by a simple transference of a knowledge proved truthful." This consists not in a "reciprocal action calculable from the outside" but configures a type of structural coupling that attains a type of "reciprocal irritation" [wechselseitige Irritation] (Luhmann 2000, p. 394). This conception implies a refusal of the conventional model of transmission of a truth, a secret or a guide to live, and a clarification of one's own purposes within the transient system created. It requires a stepping down from the rigid hierarchical distinction between therapist and client(s), respecting and accounting their beliefs and expectancies of change, interfering with its recursive patterns of selectivity. 
Therefore, "Irritation is not something that is already available as a state in the environment and acts upon the system" (Luhmann 1990b, p. 223).

As stressed by Helmut Willke, the constitution of the problem-system, and the ensuing of its recursive coupling between two social systems that irritate each other, is more dependent on the creation of the right dissents than in the obstinate search for agreements (Willke 1987a, p. 104). That transitory diagnose of dissension-points is itself open to revision in further reentries of the coupling until the multiple descriptions of that problem can achieve a way to work it through.

\section{Therapeutic Cybernetics and the Problem-System.}

There are two metaphysical assumptions that are put into question with the therapeutic models based on radical constructivism: 1) the "old" belief on pre-established essence of the subject whose true purpose must be discovered along the therapy, and 2) the idea of an order of the unconscious where a primal damage took place in the past (trauma or denial), but that holds the answer to the possibilities of the subject irrespective of his insertion in social systems.

Within systemic therapy, mostly after the "second" school of Milan, some of the premises that grounded the directive and strategic approach of the therapist have been put into question. Among others, the presumption of a neutral observation of a given system capable of asserting a way of change and cure, and the strict reduction of their therapeutic procedures to predetermined protocols, have been refused. Instead, the therapeutic intervention depends upon a contingent, recursive and dynamic coupling between communicative and psychic systems, and must have the capacity to process its self-generated uncertainties. Only this reflection on the re-entry of the therapeutic system can provide adequate anticipatory schemes that account for and promote the clients own capabilities. In our view, this demands not an altogether refusal of recursive control, but of conceiving a problem-system that departs from a new way to access problems, acknowledging the non-triviality of the psychic and communicative forms involved in the processes of change. Even if this approach abstains from distinguishing among the functionality of different models of organization, it seems to indicate a greater ability of less rigid families to find and endure necessary changes.

Prior to any intervention, the "observed system" builds meanings around the detection of an undesirable situation that requires change or termination. This internal state figures as the first condition for the constitution of a problem-system or, in K. Ludewig's terms, a helping-system [Hilfesystem] ${ }^{\mathrm{xiv}}$. That detection of the problem is extended by the therapeutic system. This provides new and improved observations on disagreements over the causes of the problem and inquires the necessary changes it must endure. Suffering is not a sufficient condition to the development of a problem-system, since individual suffering must be expressed originating new communications that motivate change. Finally, the thematization of the problem must take place in proper framework, distinguishing it from a superior order of necessity such as tragedy or fate.

The system cannot be "fixed", there is no ultimate cure or solution. The aim of therapy is not to achieve a predetermined way to deal with its functions. Through observation of the organization, the therapist accesses its operative closure defining a problem that can derive from a derailing from a previous adequate pattern. However, the change intended does not consist in restoring a given way of self-reference, but on assuring an operative closure that deals with the contingent and undesired changes on its own environment, inclusively with its relapses. The general task of a therapist is to help generate a new eigenbehaviour (Foerster and Pörksen 1999, p. 57). 
The therapist must observe and gather enough information in order to describe the distinctions that rule each pattern of interaction. Not too intrusive nor too distanced to the purposes of a given system, his intervention or irritation is not to be completely diluted or used in order to prevent any change in its recursive patterns. At the same time, as referred by K. Ludewig in his interview with Maturana, one must escape the fetishistic illusion of a Midas touch, as if the simple presence of a stranger is always enough to assure a desired change or reorganization of the patterns of a system (Ludwig and Maturana 2006: 45). Only an adequate description of the structure and organization of a system, including the way it operates recursively can grant effective modes of irritation of its settings and sequences, something that "irritates the system without destroying it"xv".

The motto of intervention is "so little as possible, so much as necessary". Let us essay a brief animal analogy in order to distinguish systemic therapy from other types of assistance. The elephant can be referred as the symbol of conventional forms of psychotherapeutic intervention ${ }^{\mathrm{xvi}}$. These are normally based on the mnemonic gathering of axioms and dogmas concerning the path and requirements of cure and assume that client's past memories and determinations are the key to present improvement. This leads to the fixing of ambitious but abstract goals that cannot be realistic attainable leading to a virtually never-ending process of therapy. Contrasting with this elephant path, various forms of systemic therapeutic intervention resemble the wasps' fly. They depart from a delimitation of the problem, not by an attempt of its exegesis, followed by a fixing of objectives. In this scheme, the therapist assumes a minimal but acute presence that we can compare to the bite of a wasp. For this analogy to be ideal we would need not only that the wasp could anticipate something more than a menacing of the present state of the bitten organism and, accordingly, that it remained alive in order to adjust the next bite. Other wasps should also assist this process, not by using their sting, helping destroying the organism, but making expert remarks on the recursive behavior that first bite induced. That is probably too much to ask for.

Taking seriously the autopoiesis of the system, and its non-triviality, requires the admission of "nonknowing" the precise goals of the system and the effects of interventions on its communicative sequences. Nonetheless, anticipation of outcomes and the selection of venues of intervention must not be dispensed. Due to the particularity of the problems and expectancies of individuals, and the unique "memories" of the system, the fragilities of customized ways of intervention are evident. Even prior to the generalized advent of second-order observation in therapy some practicians have given attention to the need of creative interventions, mainly using the resources and possibilities of the system. These resources involve their knowledge, symbols and stories that can be used in order to improve system's performance. Minuchin noted how, by renouncing the control of the therapist, the "new crew of experts" adherent to constructivism were unable to distinguish the borders of the family and induce effective and beneficial change (1991, p. 49).

Except some debilitating or threatening disorders, the patient/client plays a decisive role in all the sequences of the therapeutic process (articulating "complaints" - categorizing symptoms - planning and executing treatment - evaluating progresses). This is ultimately a consequence of the individuation of modern society, namely the absence of closed normative models guiding a great part of selective behavior. This new role of the patient and the "negotiation" inherent to treatment plans, demands an increased attention to high-order processes of reentry in order to prevent unintended or occluded distinctions guiding therapy. Additionally, this epistemic standpoint of second order cybernetics provides instruments to account for the contingent effects of therapeutic interventions. Only renewed and creative forms of therapeutic intervention, able to reinforce the responsibility of the therapist, can correspond to the requirements of this new way of conceiving adaptive and learning feedback. One of the consequences of this new approach is that systemic theory does not act on already available causes but always on effects, effects of reentry. 
Intervention cannot be reduced to using a "bag of tricks" but demands from the therapist a knowledge of some of the interests of the participants on a system. According to B. Keeney, a family therapist that made a wide journey outside common clinical practice in search for new sources of effective change: "[r]ather than reciting or enacting a predetermined script, the improvisationalist joins whatever is present and then flows with it, like a jazz musician who accepts another musician's melodic (and harmonic and rhythmic) line and elaborates it in a spontaneous and natural way" (2007, p. 888). The same author opposes the unilateral conception of the therapist as the agent of change (Keeney 2009, pp. $61 \mathrm{ff}$ ), presenting non conventional forms -it wouldn't be abusive to qualify them as awkward- of therapeutic relation that tend to mobilize patients own language, abilities and idiosyncrasies (e.g. Keeney 2009, pp. 249 ff). Adapting a maxim attributed to the Portuguese physician Abel Salazar: "the therapist that only knows about therapy, does not even know about therapy"xvii.

Systemic therapy informed by second order cybernetics has proved efficient in various domains of communication, also with applications in counseling and coaching. It has also addressed individual problems exploring the significant and determinant relations that form the context of a particular conflict or pathology, when possible convoking those persons to the sessions, and when not, resorting to their symbolization in schemes. But its observation and intervention in family systems, also due to the history of its development and implementation, remains its more distinctive and optimized application. In the following, we present some of its resources that entail an intended use of high order recursion. Furthermore, we will indicate some of the problems ensuing an inadequate (or absence of) thematization of this order of recursion in the observing system.

\section{Ilustrations.}

It is fair to say that much of the systemic therapy took seriously the difficulties inherent in first order observation of a given interaction or description of a problematic behavior or dysfunction. Certain settings make a methodical use of multiple and recursive observation/description of behavior, intermingling the interactive observation with a second order observation of behavior. This second order observation takes into account not only the guiding distinctions of the client's interactions, but also the therapist's behavior and assumptions. These resources of the transient therapeutic system will not surpass the mutual non-transparence, but provide ways to adjust the recursion of each system involved.

Among the tools of systemic therapy influenced by second order cybernetics, we will detain our analysis into Circular Questioning and the use of Reflecting Team ${ }^{\text {xviii. }}$. These are no longer conceived as used on but with the clients, even if a blurring of the distinct roles of the setting isn't necessarily intended $^{\mathrm{xix}}$. A particularity of these settings, especially of circular and reflexive questions, is their refusal to crystalize states or conditions. Instead, through conversation, their function and possible outcomes are inquired. This defies necessity and inertia, and puts in a new perspective both the relations and the elements constituting the system.

A.

Circular questions made possible a not too intrusive insertion of the therapist on the recursive communications of the "observed system", leading to a gradual (and partial) unveiling of its opacity. 
By establishing some clauses on unguided conversation, circular questions assure both the selfobservation of the member of the system, and the re-entry of the differences that guide the therapist and the family. Even without accessing the depths of individual motives, promoting the sharing of views of one's and others' motives and expectations, can facilitate the access to something close to an observation of observers and, consequently to the metarules guiding interaction.

Can this shared experience be enough to generate effective changes and, when required, guarantee new duties toward oneself and other? Therapeutic narratives show us that, despite its apparent formalism and its privileging of cognitive capacities, its unveiling of hidden problems affecting the organization and interaction of the family, tends to be highly emotional and dramatic.

Circular questioning was originally conceived in order to access a problem and formulate hypotheses for change, namely "the capacity of the therapist to conduct his investigation on the basis of feedback from the family in response to the information he solicits about relationships and, therefore, about difference and change" (Selvini-Palazzoli et al. 1980, p. 8). Only latter, particularly with the "second" Milan School, it began being used in order to, by promoting alternative processes of self-description, induce change. This has been possible with a distinction between interviewing with descriptive and reflexive questions.

Evolving from the "gossiping in the presence of others", this setting made evident hidden motives and expectations (of oneself and others) and, by exploring their ends in the system, made possible to acknowledge a positive value of certain behaviors. The new perspective on the system was could trigger spontaneous change (sometimes resisted) in the structure or organization of the system, originating a reevaluation not restricted to the cognitive level but also with considerable effects on one's emotional stances. This new perspective of the participants of the system evokes a mapping of the sequences of the system, until then unconsidered or taken as unrealistic. Therefore, it enables a distancing from what thereto was considered fixed states or causes rooted in a distant past. This contributes to "one of the tasks of systemic therapy" namely "to prevent that persons talk always using the verb being and, this way, something moves" (Cecchin 2001).

Circular questions in their various applications within therapy emphasized the capacity of a certain system to develop his own process of change. The therapist was necessary only in order to prompt a change in its premises, organization or structure. However, it remained necessary to accomplish a further operation in order to assure that prior to consider the function and goals of the system, the therapist must begin by clarifying his own purposes on the system (in this case in the therapeutic system). This means a reconsideration of the presumptions of neutrality also professed by some currents of psychoanalysis, which assume the possibility of a pure desire. The "system's therapist" would be the possessor of an ultimate power of observation, capable of interpreting interactions and communicative patterns. Such presumption had the intention of leaving the therapist outside the system which he appraises, refusing his involvement in order to prevent bias. This idea has been put into question particularly in the works of Cecchin, which stressed not only that is virtually impossible to attain or proclaim neutrality, but also that without a certain involvement and interest in the system, some of its premises remain inaccessible to the observer.

\section{B}

In 1985 Tom Andersen discontinued his reliance on practice that resorted on the observing team, and its premises of secrecy and control, replacing it for a new way to observe therapeutic interaction oriented by respect and spontaneity (Anderson 1995, p. 16). Inspired in the observations of the physiotherapist A. Bülow-Hansen, Andersen developed his idea of adequate tension between a strangeness that opens to considering new perspectives and possibilities and a familiarity that 
maintains patient's enrolment in problem-system. The change operates through recursion in two levels, on first order observation and second order consideration of the distinctions guiding interactions and punctuation. This operation of re-entry changes not only client's pre-conceptions of the problem but also the provisory diagnosis and prognosis of the therapist.

In one of the models of the Reflecting Team, the one-way mirror used to observe without being seen nor heard, is replaced by two-way mirror separating the session room from the reflecting team, composed by three of more therapists. After a period of the session, the lights of the other room go on and the sound channel is inverted so that the elements in the therapeutic room can listen the comments and conversation concerning their case.

Even if this form of assistance is supported on transparency, some clauses and guidelines must be followed and reassessed along the process. To be viable, it must fix timely limits in the question for such assumptions, so it can maintain the flow of sequences. It is important to stress that the absence of an ultimate goal makes the search for hypothesis more pressing, opening a space not of compulsory agreement but of fruitful dissentions. The challenge of the observing system seems to be to achieve an adequate distinction, the difference that enables to work through the problem. Such distinction must enable various re-entries of the system's operations. "There must be something positive", a variation of Bateson's understanding of illness recursive patterns: "in what way is this behavior meaningful?"

This model is designed in order to prevent extreme assumptions and cycles of unquestioned reinforcement of attribution/labeling and self-attribution. Judicative stance will fall upon the described pattern and not on a particular person. Like the conventional observing team, this model prevents the already referred escalation of assumptions, and instead of listening an experts report, the clients are invited to assist therapeutic reflection and take part on the hypothesizing.

This high order of recursion, is not moved by the need to establish a factual truth about a shared past event, like in the Law system, but to (re)construct and (re)align perspectives on a shared story. Remarks by the reflecting team are "intended" to be listen as suggestions instead of verdicts and engage the clients to achieve new perspectives on their problem and act accordingly. A consequence of these procedures is that any improvement between sessions is assumed as an achievement of the family and not as a confirmation of a particular intervention.

\section{High-order problems of the observing system}

High-order problems are a direct consequence of the (preferably acknowledged) responsibility of the therapist in assisting the "creation" of a certain problem or dysfunction. In his intervention or irritation, it can evoke resistance or nonproductive conflict, especially when simply imposing his views and plans without directing or preparing the conditions for cooperation.

The inattention to patterns of recursion can lead to an almost complete inversion of the roles and mechanisms that characterized the problem-system and its self-reference. Much of the entropy of the therapeutic system results from its submission the popular and unbounded demands of "warmth, understanding and at times, even love" (Cechin, Lane and Ray 1994, p. 9). These conceptions "flooded" the social semantic surrounding therapeutic practices, mostly due to the generalization of two figures described by Cecchin et. al.: the "wounded therapist" (or "wounded healer") and the "missionary therapist" (Ibid, pp. 9-25).

The first figure was considered by C. G. Jung as a primal archetype of the human psyche and purports that one can only become devoted to treat other's suffering in order to cope with his own suffering $^{\mathrm{xx}}$. This figure can be found in its modern form in the preacher or the psychoanalyst that, 
sometime in the past, suffered himself from a mental or communicative dysfunction that he surpassed through a set of steps that he now tries to reproduced on the one's he projects a similar wound. The second figure assumes to have been blessed by a personal revelation. He sees himself as the possessor of a message that he has to "transmit". If generalized, and rightly interpreted, that message will lead not only to individual salvation but also to an integral reformation of society (Johnson 2001). He imposes an ideal, an unfailing order based on natural or religious regularities, similar to the ethical model of the parts and the whole.

By suppressing the autonomy of the "observed system", both kinds of therapists tend to originate processes of symmetrical escalation in the therapeutic relation. The wounded therapist projects a lack on the client(s) and answers with love and assistance, or, worse, with pity. Blind to alternative diagnoses and nonlinear responses he tries "more of the same", inducing helplessness. The missionary therapist projects on the client a set of moral and cognitive failures that must be cured or even expiated. When the clients submit to such a worldview and fail to improve, they tend to be charged with moral failure and, sometimes, profound pathology ensues. If not refrained, these patterns of reentry only cease with complete loss of identity of the "observed system", or even with its disappearance.

Even supplemented with other observers the therapist needs "the capacity to take distance towards himself, so that this difference between self-image and self-observation can provide information on the one's operation modes" (Willke 1988, p. 48). This practice of self-description is not intended to unveil oneself, but simply to make him accountable for the way he observes his own practice ${ }^{\mathrm{xxi}}$.

\section{Conclusion. The end of therapy and the unending call for creativity}

2016, the date that Cechhin, Ray and Lane (1994: 61-6) proposed for the attempted retirement from practice of the "last family therapist" is fast approaching and, in fact, the pace of new therapeutic models, publications, seminars, does not indicate any deceleration. Intimacy generated new problems that it is frequently unable to adequately process, and we still have no final script for asserting the scope and possibility of family therapy.

This is a direct consequence of a functional differentiation and new social conditions, namely the greater (and improvable) demands imposed on the two greater axes that come to differentiate the medium Love: the couple and the offspring xxii. Not only clinical work, but also various studies of social sciences, point to the dissolution of a unique source of directive power and, concomitantly, the decaying of fixed gender roles, signs of an evolving semantic, as ultimate causes of dysfunctions. As noted by Luhmann, after the differentiation of other social systems like Economy, Law and Education, family is the only system that relates to the totality of individual attributions and expectations. One can generally refer to conflicting demands falling upon the children, that show how family lost the monopoly of children formation and education, and only desperately can it aim for its restoring. No wonder that many parents become unable to "control" their adolescent kids and insist in the same measures they used when they were children. This mixture of anxiety of control and impotency, reflect another characteristic of the family, it must account for all the occurrences involving their significant members. A similar problem holds for the relation between family and professional demands.

Various currents of systemic therapy have been very successful in showing the importance of communicative patterns in the development of pathologies and dysfunctions once exclusively attributed to individuals, or confined relations, like in folie à deux. Even various forms of therapy based on linear approaches, have been very sensitive to those rapid changes, accepting, consciously or not, the need to acknowledge conflictive demands and the responsibility to endorse views on 
asymmetric roles and adequate parenting models. This meant that, even assuming the existence of seemingly straightforward answers to described problems, the concept of equilibrium could not be assumed as the end of the therapeutic change, if considered irrespective of the differences assuring the stability of the system.

With the adaptation of second-order cybernetics, these problems could be considered much more clearly, leading to a deeper quest for self-evaluation of the system's assumptions. Much of the apparently never-ending prospect of the field of family therapy, derive from the opportunities entailed in the recursion of the family and of the therapeutic or problem-system itself. It enables not simply a way to describe patterns, but the ability to access their blind distinctions and create new perspectives on those patterns without necessarily denying or replacing them. High order of recursion refers the way the distinctions guiding the therapeutic system reenter the system in view of its results in the punctuation of the system. This retroactive observation of pre-concepts, assumptions and intervention is provided by systemic therapy but is present, more or less explicitly, in other therapeutic currents.

Much of the advances in clinical understanding seem to have only been possible with new research no longer constrained by exterior pressures for clinical results, namely economic pressures that interfere in the quality of the therapeutic relation. This was a decisive reason for the advances of Milan School. With few exceptions, it does not seem easy to allocate the kind of resources required by some models based on observation of observers, teams of therapists, supervisors or advisory boards. Nevertheless, these new models had a reflex in ordinary clinical practice, turning attention into the need of inspecting one's own premises. On the other hand, they accepted the possibility of completely covering the blind side of an intervention, and the need to assume timely decision without stopping the flow of sequences.

As we saw, the success of the intervention seems to be dependent on the tension between a familiarity and estrangement, granting the auto and hetero descriptions of something close to a social function within modern society.

The observing system of therapy operates through recursive feedback of its defining and operative distinctions. Interaction between therapist and client presents the circumstances to which the system operates. Its sequences do not obey a predetermined scheme or a rigid script but adjust to the assessment, treatment and reevaluation of the problem. Such adjustment is dependent upon the re-entry of the previous operations into the system.

What is new in this conception of recursion is not that it evaluates progress contrasting it with anticipated outcomes, that was already the case in the circularity of first order cybernetics. In a nontrivial system, like the therapeutic/problem-system, that recursion is not guided by a previously determined production or performance achieved through negative entropy. In order to achieve something like a adequate performance or equilibrium, this kind of system has to attend to its own internal dynamical states. Here observations do not repeat or reproduce previous sequences, but adapt to evolving circumstances through learning.

\section{References}

Andersen, Tom (1987). The reflecting team: Dialogue and meta-dialogue in clinical work. Family Process, 26 (4): 415-428. 
(1995). "Reflecting processes; acts of informing and forming: you can borrow my eyes, but you must not take them away from me". In: Steven Friedman (ed.), The Reflecting Team in Action: Collaborative Practice in Family Therapy. New York: Guilford Press, 11-37.

Anderson, Harlene and Harold Goolishian (1988). Human systems as linguistic systems: Preliminary and evolving ideas about the implications for clinical theory. Family Process, 27, 371-394.

Anderson, Harlene and Per Jensen (2007). Innovations in the Reflecting Process. The Inspirations of Tom Andersen. London: Karnac.

Baecker, Dirk (2005). Form und Formen der Kommunikation. Frankfurt am Main: Suhrkamp. Balsemão Pires, Edmundo (2013). The epistemological meaning of Luhmann's critique of classical ontology. Systems. 1 (1), pp. 5-20.

Bateson, Gregory (1978). The birth of a matrix or double bind and epistemology. In: Milton Berger (Ed.). Beyond the double bind: Communication and family systems, theories, and techniques with schizophrenics. New York: Brunner/Mazel, 39-64.

_. (2000). Steps to an ecology of mind, revised edition. Chicago: University of Chicago Press.

Barnes, Graham (1994). Justice, Love and Wisdom. Linking Psychotherapy to Second-Order Cybernetics. Zagreb: Medicinska Naklada.

. (2000). Retrieving a Flourishing Psychotherapy: A Transactional-Cybernetic

Meditation on Transactional Analysis. Transactional Analysis Journal, 30 (3), 233-47.

. (2008). An introduction to Dialogotherapy. Kairos. Slovenian Journal of Psychotherapy, 2 (3-4), 25-59.

Beer, Stafford (1986). Recursions of Power. In: R. Trappl, Ed., Power, autonomy, utopia. New directions toward complex systems. New York: Plenum Press, , 3-17.

Buchinger, Eva (2006). The sociological concept of autopoiesis: Biological and philosophical basics and governance relevance. Kybernetes, 35 (3/4), 36o-374.

. (2012). Luhmann and the Constructivist Heritage. A Critical Reflection. Constructivist Foundations. 8 (1), 19-37.

Cecchin, Gianfranco (1987). Hypothesising, Circularity and Neutrality Revisited: an Invitation to Curiosity. Family Process. 26 (4), 405-13.

Cecchin, Gianfranco, Gerry Lane and Wendel A. Ray (1994). The cybernetics of prejudices in the practice of psychotherapy. London: Karnac Books.

Cecchin, Gianfranco (2001). "Comunicazioni sovrapposte nel gioco del paradosso" Communication to il gruppo Fuori Programma. Retrieved from:

http://digilander.libero.it/LaTerraSanta/lete/voci/cecchinı.html 
Erickson, Milton (1954/1980). Special Techniques of Brief Hypnotherapy. The Collected Papers of Milton H. Erickson on Hypnosis. Vol IV: Innovative Hypnotherapy of Milton H. Erickson. Ed. by E. Rossi. New York: Irvington, 149-173.

Foerster, Heinz von (1984). "Principles of Self-Organization - In a Socio-Managerial Context”. In: H. Ulrich und G.J.B. Probst (Hrsg.), Self-Organization and Management of Social Systems. Berlin Heidelberg-New York: Springer, 2-24.

. (1984 b). On Constructing a Reality. In: The Invented Reality: How Do We Know What We Believe We Know? (Contributions to Constructivism). Paul Watzlawick (Ed.) New York: W. W. Norton \& Company, 41-62.

. (2003 [1979]). “Cybernetics of Cybernetics”. In: Id., Understanding Understanding. Essays on Cybernetics and Cognition. New York: Springer, 283-283.

. (2003 [1991]). "Ethics and Second-Order Cybernetics". In: Id., Understanding Understanding. Essays on Cybernetics and Cognition. New York: Springer, 287-304.

Foerster, Heinz von and Bernhard Pörksen (1999). Wahrheit ist die Erfindung eines Lügners. Gespräche für Skeptiker. Heidelberg: Carl-Auer.

Golann, Stuart (1988). On Second-Order Family Therapy. Family Process. 27, 51-65.

Hoffman, L. (1985). Beyond power and control: Toward a second-order family systems therapy. Family Systems Medicine, 3, 381-396.

Jackson, Don (1965). The study of the family. Family Process, 4 (1), 1-20.

Johnson, Scott (2001). Family Therapy saves the Planet: Messianic tendencies in the Family systems literature. Journal of Marital and Family Therapy. 27 (1), 3-11.

Kauffman, Louis H. (1987). Self-reference and recursive forms. Journal of Social and Biological Structure. 10, 53-72.

Keeney, Bradford (1983). Aesthetics of Change. New York: Guilford. . (2007). Batesonian epistemology, Bushman n/om-kxaosi, and rock art. Kybernetes. The International Journal of Systems, Cybernetics and Management Science. 36 (7/8). Monika S. Broecker and Georg Ivanovas (guest eds.), 884-904.

. (2009). The Creative Therapist: The Art of Awakening A Session. London: Routledge.

Keeney, Bradford and Jeffrey Ross (1985). Mind in Therapy. Constructing Systemic Family Therapies. New York. Basic Books.

Lankton, Carol (1985). “Generative Change: Beyond Symptomatic Relief”. In: J. Zeig (Ed.), Ericksonian Psychotherapy. Vol. I: Structures, New York: Brunner/Mazel, pp. 137-170.

Lee, Richard E. (2002). Sociocybernetic Approaches for a Changing World: An Introduction. International Review of Sociology, 12 (2), 187-191.

Ludewig, Kurt and Humberto R. Maturana, (2006 [1992]). Gespräche mit Humberto Maturana. Fragen zur Biologie, Psychotherapie und den Baum der Erkenntnis, oder: die 
Fragen, die ich immer stellen wollte. vollständig revidierte Version. Retrieved from: http://www.systemagazin.de/bibliothek/texte/ludewig-maturana.pdf

Ludewig, Kurt (1987). „Vom Stellenwert diagnostischer Maßnahmen in Systemischem Verständnis von Therapie“. In: Systeme erkennen Systeme. Individuelle, soziale und methodische Bedingungen systemischer Diagnostik. G. Schiepek (Hrsg.). München, Weinheim: Psychologie Verlags Union.

Ludewig, Kurt (1992). Systemische Therapie. Grundlagen klinischer Theorie und Praxis. Stuttgart: Klett-Cotta.

Luhmann, Niklas (1982). Liebe als Passion. Zur Codierung von Intimität. Frankfurt a.M.: Suhrkamp.

. (1983). „Anspruchsinflation im Krankheitssystem: Eine Stellungnahme aus gesellschaftstheoretischer Sicht“. In: Herder-Dorneich, Philipp; Schuller, Alexander (Hrsg.), Die Anspruchsspirale. Schicksal oder Systemdefekt. Stuttgart: Kohlhammer, pp. 28-49.

(1988). “Therapeutische Systeme - Fragen an Niklas Luhmann”. In: F. B. Simon (Hrsg.), Lebende Systeme: Wirklichkeitskonstruktionen in der Systemischen Therapie.

Berlin/Heidelberg: Springer-Verlag, 125-138.

. (1990). Soziologische Aufklärung. Band 5: Konstruktivistische Perspektiven. Opladen: Westdeutscher Verlag.

. (1990 a)."Sozialssystem Familie” in Id., Soziologische Aufklärung. Band 5. Opladen: Westdeutscher Verlag, pp. 196-217.

. (199o b). „Glück und Unglück der Kommunikation in Familien: Zur Genese von Pathologien“ in Id., Soziologische Aufklärung. Band 5. Opladen: Westdeutscher Verlag, pp. 218-227.

. (1991). „Wie lassen sich latente Strukturen beobachten?“. In: Das Auge des Betrachters: Beiträge zum Konstruktivismus. Festschrift für Heinz von Foerster. P. Watzlawick and P. Krieg (eds.), München: Piper, pp. 61-74.

. (200o). Die Politik der Gesellschaft. Frankfurt a.M.: Suhrkamp.

. (2001). Aufsätze und Reden. Hrsg. von Oliver Jahraus. Stuttgart: Reclam.

. (2008 [1969]). Liebe - eine Übung. Frankfurt a.M.: Suhrkamp.

Lutterer, Wolfram (2005). Systemics: The Social Aspects of Cybernetics. Kybernetes: The International Journal of Systems E Cybernetics, 34 (3), 497-507.

Mackinnon, Laurie K. and Dusty Miller (1987). The new epistemology and the Milan approach: Feminist and Sociopolitical considerations. Journal of Marital and Family Therapy. $13(2), 139-155$.

Mascareño, Aldo (2011). Sociología de la intervención: orientación sistémica contextual. Revista Mad. Magister En Análisis Sistémico Aplicado a La Sociedad, 25, 1-33. Retrieved from: http://www.revistamad.uchile.cl/index.php/RMAD/article/viewFile/15656/pdf 
Minuchin, Salvador (1991). The seductions of constructivism. Family Therapy Networker. 15(3), 47-50.

Minuchin, Salvador, and Charles Fishman (1981). Family therapy techniques. Cambridge, MA: Harvard University Press.

Minuchin, Salvador, Wai-Yung Lee and George Simon (2006 [1996]). Mastering Family Therapy. Journeys of Growth and Transformation. $2^{\text {nd }}$ Ed. New Jersey: John Wiley \& Sons, Inc.

Pask, Gordon (1969). “The meaning of cybernetics in the behavioral sciences”. In J. Rose (Ed.), Progress of Cybernetics. New York: Gordon \& Breach.

Paetau, Michael (2013). Niklas Luhmann and Cybernetics. Journal of Sociocybernetics, 1, 75103.

Rice, Cecil A. (2011). The Psychotherapist as "Wounded Healer": A Modern Expression of an Ancient Tradition. In: Robert Klein, Harold Bernard and Victor Schermer (Eds.), On Becoming a Psychotherapist. The Personal and Professional Journey. New York: Oxford University Press, 165-189.

Selvini-Palazzoli, Mara, Luigi Boscolo, Gianfranco Cecchin and Giuliana Prata (1980). Hypothesizing-circularity-neutrality: Three guidelines for the conductor of the session. Family Process, 19, 3-12.

Schiepek, Günther (1991). Systemtheorie der Klinischen Psychologie. Beitrage zu ausgewählten Problemstellungen. Braunschweig: Vieweg.

Scott, Bernard (2004). Second-order cybernetics: an historical introduction. Kybernetes. The International Journal of Systems, Cybernetics and Management Science. 33 (9/10), 1365-1378.

Spencer-Brown, George (1969). Laws of Form. London: George Allen, Unwin Ltd.

Stierlin, Helm (1988). „Zur Beziehung zwischen Einzelperson und System: der Begriff "Individuation" in systemischer Sieht". In: L. Reiter, E.J. Brunner und S. Reiter-Theil (Hrsg.), Von der Familientherapie zur systemischen Perspektive., Berlin-Heidelberg-New York: Springer, 3-19.

Teubner, Gunther and Helmut Willke (1997). Teubner's and Willke's Presentation June 1997. Can Social Systems be Viewed as Autopoietic? London. Retrieved from:

http://www.lse.ac.uk/researchAndExpertise/units/complexity/StudyGroups/reportg7june.as $\mathrm{px}$

Tomm, Karl (1987). Interventive Interviewing: Part II, reflexive questioning as a means to enable self healing. Family Process. 26, 167-183.

Valéry, Paul (1960). Choses Tues, In : CEuvres II, Paris : La Pléiade.

Watzlawick, Paul, Janet H. Beavin and Don D. Jackson, (1967). Pragmatics of human communication: A study of interactional patterns, pathologies, and paradoxes. New York: W.W. Norton \& Company. 
Watzlawick, Paul, John Weakland and Richard Fisch (1974). Change: Principles of problem formation and problem resolution. New York: W.W. Norton.

Watzlawick, Paul (1991). „Krankmachende Kommunikation und ihre Veränderung - ein Beitrag zur Krankheitsbewältigung“. In: Was macht den Menschen krank? : 18 kritische Analysen, Ivan Illich and Klaus Jork (Eds.), Basel: Springer. pp. 135-140.

. (1993 [1990]). If you desire to see, learn how to act. In: Giorgio Nardone and Paul Watzlawick (Eds.), The art of change. San Francisco: Jossey-Bass, 1-16.

Whitaker, Robert (2010). Anatomy of an epidemic: Magic bullets, psychiatric drugs, and the astonishing rise of mental illness in America. New York: Crown Publishers.

Willke, Helmut (1984). Zum Problem der Intervention in selbstreferentielle Systeme. Zeitschrift für systematische Therapie. 2, 191-200.

. (1987a). „Systembeobachtung, System Diagnose, Systemintervention - Weiße Locher in schwarzen Kasten?“ In: G. Schiepek (Ed.), Systeme erkennen Systeme. Psychologie Verlags Union, München-Weinheim, 94-114.

. (1987b) Strategien der Intervention in autonome Systeme. In: Baecker D., J.

Markowitz, R. Stichweh, H. Tyrell und H.Willke (Hrsg.) Theorie als Passion. Niklas Luhmann zum 6o. Geburtstag. Suhrkamp, Frankfurt am Main, 333-361.

. (1988). Systemtheoretische Grundlagen des therapeutischen Eingriffs in autonome Systeme. In: L. Reiter, E.J. Brunner und S. Reiter-Theil (Hrsg.), Von der Familientherapie zur systemischen Perspektive. Berlin/Heidelberg/NewYork: Springer, 41-50.

\footnotetext{
i Although outside the scope of the present study, today we have an immense amount of literature devoted to the ambiguous effects of the introduction and improvements of Psychiatric drugs in treating mental illness. See for instance the Anatomy of an epidemic by Robert Whitaker.

ii A rich interpretation of von Foerster's imperative in the realm of therapy is provided by Watzlawick (1993).

iii This and the subsequent translations from German texts have been made by the author.

${ }^{\text {iv }}$ As referred by Graham Barnes, in a work that Professor Bernard Scott had the kindness to brought to my attention, Erickson: "was participating in the experimental epistemology that cybernetics proposed for Bateson. Erickson did not teach patients new theory or a new language; he responded to the unique communication pattern of each patient" (1994, p. 111).

$\checkmark$ One of the most frequent instance of those knots is the double bind situation described and explained by Bateson (1978).

vi Paetau (2013) offered a reading of the way by which Luhmann absorbed and adapted some of the main ideas of cybernetics in his theory of social systems, attending to the way different systems and organizations depend upon constancy and invariance along their operations.

vii I have to thank Reviewer A for posing the pertinent question of knowing if Luhmann's view on the family changes substantially between his early work and latter writings. One can say with some certainty that his Liebe als Passion, an historical reading of the semantics of passion and intimacy is more confusing than the initial clear writing on Love.
} 
However, in order to understand the conditions of therapeutic intervention in the basal circularity of the family system, the latter work of Luhmann provides a better-equipped theory for addressing the uncertain outcomes of the irritation of the communicative sequences of intimacy.

viii In the words of Eva Buchinger: "The form person includes the body because of the structural coupling between the psychic system and its physical basis and therefore gains duration beyond the psychic reproduction. It is not a system, but a social-psychological attribution with the function of reducing uncertainty in social interaction by representing individualized behavioral constraints" (2012: 26).

${ }^{\text {ix }}$ As we can asseverate from the references he provides, Luhmann is very acquainted, among others, with the works of G. Bateson, P. Watzlawick, F. Simon, K. Ludewig and the Milan School.

" In a poignant assertion, Luhmann affirms that: "In the perspective here preferred, not only is the extrafamiliar [außerfamiliale] environment external, but also body and soul, life and consciousness of the family members" (Luhmann 1990a, p. 201).

${ }^{x i}$ Significantly inspired by the psychiatrist R. Laing, and his understanding of data as always a function of capta, Spencer-Brown underlined that all experience derives from the distinctions that order it (1969 xxii-xxiii). His calculus of form continues to provide a framework to understand both the constitution of the borders of the therapeutic system and its operations of reentry, that is, the conditions of self-reference.

xii « [C]e mélange extraordinaire de la crainte de n'être pas compris avec la terreur d’être compris » (Valéry 1960, p. 493).

xiii "Concerning therapy, the relation of recursion between action and cognition proves highly meaningful, since cognitive changes, that result from the self-perception that one's action and its consequences are in conflict, may not be grounded on the psychic system of an individual" (Schiepek 1991, p. 321)

${ }^{\text {xiv }}$ This author distinguishes among 4 different kinds of assistance with distinct prerogatives: Management [Anleitung]; Counselling; Accompaniment [Begleitung] and, finally, therapy itself (1992, p. 123).

${ }^{x v}$ „Das system stören, aber nicht zestoren“.

xvi The reader can get a stronger sense of the analogy if recalling the family in the title page of Lacan's first Seminaire: Les écrits techniques de Freud.

xvii Originally: "o médico que só sabe de Medicina, nem de medicina sabe".

xviii Along with the importance of rituals inherited from the structural approach, we can refer as specific or originated in systemic approach, Reframing (finding the positive signs), the Genogram, cooperative Hypothesizing, Metaphoric modelling (mostly of statues) and Externalization.

xix In his critical reading of the evolution of E. Berne's transactional analysis, Barnes affirms that: "[j]ust as patients in therapy may change as a result of seeing themselves through the eyes of their therapists, so we may change ourselves and our theory by seeing ourselves and our theory through the eyes of others" (2000, p. 244). This dialogical framework of therapy will be further developed in latter works (Barnes 2008).

${ }^{\mathrm{xx}}$ For a recent review of this archetype see: Rice 2011.

${ }^{x \times i}$ Gunther Teubner has also explored this aspect in his application of the concepts of autopoietic operational closure as the condition for heteroreference in the differentiation of the Law system (Teubner and Willke 1997).

xxii There are of course other problematic relations outside couple and formation dysfunctions. This "cutting" preserves only the core of "functions" society demands of the family after the dissolution of the old forms of domestic community. 